\title{
Pelatihan Model Pembelajaran Speaking dengan Communicative Approach Bagi Guru-Guru Bahasa Inggris di Kabupaten Lampung Selatan
}

\author{
Bambang Setiyadi, Mahpul, Sukirlan, Gede Eka Putrawan
}

English Education, Lampung University, Bandar Lampung, 35145, Lampung, Indonesia

\begin{abstract}
.
The speaking learning model with communicative approach has been widely adopted in various countries as a method of learning English because speaking learning with communicative approach proved effective to facilitate students actively involved in the learning process of English, especially speaking. The effectiveness / success of speaking learning by communicative approach as a way of English education in helping students improve speaking skills is evidenced by the discovery of some research tried in various countries where English as a foreign language. However, in Indonesia this method is still not popular and very few teachers or practitioners apply this method. Therefore, this community service activity aims to help English teachers in South Lampung Regency improve insight and knowledge about the development/creation of a speaking learning model based on communicative approach through training and workshops by presenting material development of task-based speaking teaching materials theoretically; and conduct simulations of the development of task-based speaking teaching materials. The results of the training showed that the participants of this training gained real efficacy is an increase in professionalism in order to be able to correct the quality of the English education process, especially speaking so that the dialogue skills of students in schools face an increase. Prolonged similar training in the future still really needs to be tried.
\end{abstract}

\section{Keywords.}

communicative approach, speaking learning model, English Teacher

\section{PENDAHULUAN}

Kemampuan berbicara (speaking) bahasa Inggris para siswa pada bebrbagai jenjang pendidikan (SMP, SMA, SMK, dan perguruan tinggi) secara umum dianggap belum memuaskan. Sebagian besar siwa tidak mampu berkomunikasi secara lisan dalam bahasa Inggris dengan baik walaupun pada tataran komunikasi yang sederhana $[1,2]$. Rendahnya tingkat kemampuan berbicara bahasa Inggris menjadi masalah umum tidak hanya dialami para siswa di Indonesia tapi juga pembelajar dari negara-negara lain terutama di mana bahasa Inggris sebagai bahasa asing. Beberapa hasil studi diberbagai negara Asia seperti,

\section{* Corresponding author: bambang_setiyadi76@yahoo.co.id}

Received 06 October 2021; Received in revised form 18 October 2021; Accepted 20 October 2021 
Taiwan, China, dan Korea, Indonesia [3-6] menunjukan bahwa salah satu faktor utama penyebab rendahnya kemampuan berbicara mahasiswa dalam bahasa Inggris adalah kurang tepatnya model pembelajaran yang guru laksankan selama ini. Hal ini mengindikasikan bahwa metode atau model pembelajaran yang selama ini digunakan belum mampu membangkitkan siswa/pembelajar berpartisipasi aktif untuk berbicara dalam bahasa Inggris.

Pembelajaran bahasa Inggris dengan Communicative Approach yang sering dikenal dengan istilah task-based language teaching (TBLT) diadaptasi dari gagasan pendekatan komunikatif dalam pembelajaran bahasa Inggris yang digagas oleh Brumfit \& Johnson (1979) [7] dan kemudian dikembangkan oleh sejumlah peneliti dan penyusun silabus menjadi sebuah model pembelajaran komunikatif yang menekankan pada makna (meaning) dan aspek bahasa (forms) [8-16]. Istilah task adalah aktifitas pembelajaran bahasa secara komunikatif [17].

Van den Branden et al., (2009) menyatakan bahwa pembelajaran speaking dengan communicative approach merupakan sebuah model pembelajaran bahasa yang berdasarkan pada aktifitas yang holistik (holistic activities), makna (meaning-based activities), dan berfokus pada siswa (learner-driven activities) [16]. Penggunaan pembelajaran speaking dengan communicative approach dalam pembelajaran bahasa Inggris berimplikasi pada meningkatnya studi atau riset terkait pengunaan pembelajaran speaking dengan communicative approach [18-26].

Pendekatan pembelajaran Communicative Approach merupakan sebuah metode yang telah terbukti efektif untuk meningkatkan kemampuan siswa berbicara (speaking) dalam bahasa Inggris [3,27]. pembelajaran speaking dengan communicative approach merupakan pendekatan pembelajaran bahasa dengan paradigma bahwa proses pembelajaran berbahasa (Use) yaitu model pembelajaran yang merefleksikan penggunaan bahasa sebagai alat komunikasi dalam kehidupan nyata (real-life activities) dengan melibatkan peran aktif pembelajar lebih penting daripada belajar ilmu bahasa (Usage) $[28,16]$. Proses pembelajaran berbasis task menekankan pada penguasaan makna (meaning) dan juga aspek bahasa (forms) $[8,10,12]$.

Model pembelajaran speaking dengan communicative approach sudah diadopsi secara luas di berbagai negara sperti: India, China, Jepang, Arab, sebagai metode pembelajaran bahasa Inggris karena pembelajaran speaking dengan communicative approach sudah terbukti efektif mampu memfasilitasi siswa terlibat akktif dalam proses pembelajaran bahasa Inggris khususnya berbicara. Efektifitas/keberhasilan pembelajaran speaking dengan communicative approach sebagai metode pembelajaran bahasa Inggris dalam membantu para siswa meningkatkan kemampuan speaking dibuktikan dengan temuan beberapa penelitian yang dilakukan di berbagai negara terutama di mana bahasa Inggris sebagai bahasa asing [12,14,21-23,29].

Dalam kaitannya dengan kegiatan pengabdian kepada masyarakat ini, communicative yang diterapkan dalam pelatihan bahasa Inggris bagi masyarakat dan praktisi pariwisata adalah communicative approach yang didasari oleh pemikiran bahwa kemampuan menggunakan bahasa dalam komunikasi merupakan suatu tujuan yang harus dicapai dalam pembelajaran bahasa. Bahasa tidak hanya dipandang sebagai seperangkat kaidah tetapi lebih luas lagi yaitu sebagai sarana untuk communicative. Hal ini berarti bahasa diletakkan sesuai fungsinya yaitu fungsi communicative. Menurut Littlewood 1981 dalam (Eli Hinkel, 2011) pemikiran communicative approac didasarkan pada pemikiran bahwa pendekatan komunikatif membuka diri bagi pandangan yang lebih luas tentang bahasa [30]. Artinya, orang melihat bahasa tidak terbatas pada tata bahasa dan kosakata, namun juga 
pada fungsi komunikatifnya.

Communicative approach juga membuka diri bagi pandangan yang luas dalam pembelajaran bahasa. Ini berarti bahwa mengajarkan bahasa tidak cukup dengan memberikan siswa bagaimana bentuk-bentuk bahasa asing, tetapi siswa harus mampu mengembangkan cara-cara menerapkan bentuk-bentuk itu sesuai dengan fungsi bahasa sebagai sarana komunikasi dalam situasi dan waktu yang tepat. Pendekatan komunikatif berorientasi pada proses belajar-mengajar bahasa berdasarkan tugas dan fungsi berkomunikasi. Prinsip dasar pendekatan komunikatif ialah: a) materi harus terdiri dari bahasa sebagai alat berkomunikasi, b) desain materi harus lebih menekankan proses belajar-mengajar dan bukan pokok bahasan, dan c) materi harus memberi dorongan kepada siswa untuk berkomunikasi secara wajar [31].

Strategi belajar-mengajar dalam pendekatan komunikatif didasarkan pada cara belajar siswa aktif, yang sekarang dikenal dengan istilah student-centered learning (SCL). Cara belajar aktif merupakan perkembangan dari teori Dewey learning by doing (1854-1952) [32]. Dewey sangat tidak setuju dengan belajar dengan menghafal (rote learning). Dewey menerapkan prinsip-prinsip yaitu peserta didik perlu terlibat dalam proses belajar secara spontan/terlibat secara aktif dalam proses belajar mengajar (learning by doing). Dengan demikian diharapkan kemampuan berkomunikasi baik lisan dan tulisan siswa meningkat.

Beberapa tahun terakhir, model pembelajaran berbasis task dikembangkan berdasarkan the Cognition Hypothesis [20-23,29,33]. The Cognition Hypothesis menjelaskan pentingnya peran kognitif dalam meningkatkan kemampuan siswa/pembelajar dalam berbahasa.

Menurut the Cognition Hypothesis, model pembelajaran berbasis task sebaiknya dikembangkan berdasarkan tiga faktor utama penentu keberasilan pembelajaran bahasa Inggris yaitu: faktor kognitif (cognitive factors) yang juga dikenal dengan istilah task complexity, faktor interaktif (interactive factors) yang disebut dengan task condition, dan faktor siswa (learner factors) yang juga disebut task difficulty. Ketiga faktor tersebut dikenal dengan Triadic Componential Framework seperti terlihat pada table 1.

Tabel 1. Triadic Componential Framework

\begin{tabular}{|c|c|c|}
\hline $\begin{array}{l}\text { Task complexity } \\
\end{array}$ & $\begin{array}{l}\text { Task conditions } \\
\end{array}$ & $\begin{array}{l}\text { Task difficulty } \\
\end{array}$ \\
\hline (Cognitive factors) & (Interactive factors) & (Learner factors) \\
\hline a) resource-directing & a) participation variable & a) affective variables \\
\hline e.g., +/- few elements & e.g., one-way/two-way e.g., & motivation \\
\hline +/- here-and now & convergent/divergent & anxiety \\
\hline +/- no reasoning demands & open/closed & confidence \\
\hline b) resource-depleting & b) participant variables & b) ability variables \\
\hline e.g., +/- planning & e.g., gender & e.g., aptitude \\
\hline$+/-$ single task & familiarity & proficiency \\
\hline +/- prior knowledge & power/solidarity & Intelligence \\
\hline $\begin{array}{l}\text { Sequencing criteria ---- } \\
\text { Prospective decisions } \\
\text { about task unit }\end{array}$ & \multicolumn{2}{|c|}{$\begin{array}{l}\text { Methodological criteria } \\
\text { on-line decision } \\
\text { about pairs and groups }\end{array}$} \\
\hline
\end{tabular}

Oleh karena itu, pengabdian kepada masyarakat ini penting untuk dilaksanakan untuk membantu guru dengan memberikan dengan memberi pelatihan bahasa Inggris pariwisata (English for Tourism) komunikatif guru agar mampu berkomunikasi dan menyampaikan informasi dengan benar kepada para siswa ketika memberikan pembelajaran guna menjadi 
lebih menarik.

\section{SOLUSI DAN TARGET}

Robinson menyarankan bahwa faktor kognitif atau Communicative approach sebaiknya menjadi faktor utama dalam mengembangkan model pembelajaran berbasis task karena faktor lainya terutama faktor pembelajar (learner factors) seperti motivasi, sulit dipredikasi sejak awal. Menurut Robinson, faktor kognitif (the resource-directing dan the resourcedirecting) dapat berperan dalam meningkatkan dan mengurangi beban psikologis siswa dalam melaksanakan berbagai aktifitas pembelajaran. Menururt Robinson, dimensi the resource-directing merupakan faktor kognitif yang secara khusus berperan mengarahkan siswa pada aspek linguistik. Sebaliknya dimensi the resource-depleting merupakan faktor kognitif yang juga dapat mempengaruhi kondisi psikologis siswa tapi tidak berperan mengarahkan siswa pada aspek linguistik. Penelitian model pembelajaran berbasis task sebagian besar berorientasi pada mencari efektifitas peran faktor kognitif yang dikaitkan dengan kemampuan berbahasa siswa (learner performance) dalam hal kelancaran (fluency), kompleksitas (complexity), dan akurasi (accuracy) [20-23,29,33].

Robinson berpendapat bahwa kedua dimensi faktor kognitif (the resource directing dan the resource depleting) seperti ditunjukan pada Gambar 1, dapat "dimanipulasi" untuk memfasilitasi sisiwa meningkatakan kemampuan berbahasa. Selanjutnya, Robinson berargumen bahwa task yang dibuat komplek secara kognitif khususnya dimensi the resource-directing akan meningkatakan akurasi (accuracy), dan komplesitas (complexity) tapi mengurangi tingkat kelancaran (fluency). Sebaliknya, menurut Robinson, task yang dibuat komplek secara kogntif khususnya dimensi the resource-depleting akan mengurangi tingkat kelancaran (fluency), kompleksitas (complexity), dan akurasi (accuracy) dalam berbahasa [22,33].

Banyak hasil penelitian menunjukan efektifitas model pembelajaran berbasis task terhadap kemampuan berbicara dalam hal kelancaran (fluency), kompleksitas (complexity), dan akurasi (accuracy) ujaran siswa/pembelajar yang dihasilkan dari sebuah task. Sebagai contoh.penelitian yang secara khusus meneliti pengaruh peran faktor kognitif khususnya dimensi the resource-depleting [25,26,34-36]; dimensi the resource-directing [20,37,38]; gabungan dua dimensi: the resource-directing dan the resource-depleting [3,19,27]; persepsi terhadap penggunaan model pembelajaran berbasis task [39].

\section{PELAKSANAAN}

Khalayak sasaran kegiatan pelatihan pengembangan/pembuatan model pembelajaran speaking (berbicara) dengan pendekatan Communicative Approach adalah 30 orang guru Bahasa Inggris di kecamatan Sidomulyo, Kabupaten Lampung Selatan.

Pelatihan pengembangan metode pembelajaran speaking berbasis task dilaksanakan menggunakan metode:

1. Ceramah tentang prinsip-prinsip pembelajaran dengan Communicative Approach serta penjelasan tentang kaidah pengembangan model pembelajaran speaking berbasis task diikuti dengan tanya jawab dan diskusi.

2. Pemberian contoh model pembelajaran speaking dengan Communicative Approach.

3. Pemberian tugas untuk mendesain model pembelajaran dengan Communicative Approach dengan dibimbing oleh para instruktur. 
4. Praktek simulasi model pembelajaran speaking dengan Communicative Approach Instruktur memberikan masukan atas kelemahan dan kelebihan model pembelajaran.

Beberapa kegitaan akan dilakukakn untuk mengetahui efektifitas hasil pelatihan pengembangan model pembelajaran speaking berbasis task, sebagai berikut:

\section{Pre-Test}

Pre-test berupa questionnaire (close dan open-ended questions). Para guru diminta untuk menjawab pertanyaan terkait pengetahuan mereka tentang pendekatan/model pembelajaran bahasa Inggris terutama pembelajaran speaking dengan communicative approach. Hal ini dilakukan untuk mengetahui kemampuan awal para guru tentang pembelajaran speaking dengan communicative approach secara umum maupun pembelajaran speaking dengan communicative approach terkait khusus pembelajaran speaking.

\section{Observasi}

Observasi akan dilakukan pada saat pelatihan berlangsung untuk mengetahui kesulitan/kendala yang dihadapai para guru dalam mendesain dan mengimplementasikan model pembelajaran yang dibuat.

\section{Post-Test}

Soal post-test pada dasarnya sama dengan soal pre-test yaitu berupa questionnaire (close dan open-ended questions) tetapi dalam post-test peserta diminta untuk mendesian model pembelajaran dengan topik yang berbeda dengan yang sudah dipresentasikan/didemosntrasikan di depan kelas.

Kemudian untuk mendapatkan hasil yang lebih baik bagi guru dalam memberikan materi dilakukan dengan model pembelajaran bahasa Inggris terutama pembelajaran speaking dengan communicative approach diantaranya :(1) memberikan pelatihan dan workshop dengan menyajikan materi mengenai pentingnya bahasa Inggris sebagai model pembelajaran bahasa Inggris terutama pembelajaran speaking dengan communicative approach guna meningkatkan minat siswa untuk belajar, dan (2) memberikan pelatihan bahasa Inggris dengan pembelajaran speaking dengan communicative approach kepada guru di Kabupaten Lampung Selatan secara teori dan praktik melalui simulasi, dialog dan bermain peran, serta diskusi.

\section{HASIL DAN PEMBAHASAN}

Kegiatan pengabdian kepada masyarakat yang berjudul "pelatihan model pembelajaran speaking dengan communicative approach bagi guru-guru bahasa inggris di Kabupaten Lampung Selatan" ini dilaksanakan berdasarkan studi pendahuluan melalui wawancara dengan guru-guru bahasa Inggris. Sebagian besar guru bahasa Inggris tersebut belum memahami model pembelajaran speaking dengan communicative approach sehingga mereka kurang percaya diri dalam menerapkan metode tersebut, termasuk para guru Bahasa Inggris di Kabupaten Lampung Selatan. Akibatnya mereka tetap menerapkan model/pendekatan pembelajaran bahasa Inggris yang mengutamakan penguasaan aspek bahasa (forms) yang terbukti kurang mampu memfasilitasi siswa dalam meningkatan kemampuan berbicara dalam bahasa Inggris. 
Selanjutnya, beberapa langkah diambil oleh tim pengabdian yang meliputi: (1) membuat proposal pengabdian kepada masyarakat yang ditujukan kepada Universitas Lampung, (2) melakukan koordinasi dengan mitra pengabdian, (3) menyusun materi pelatihan, dan (4) melaksanakan kegiatan pelatihan.

Di awal dan akhir pelatihan, para guru diberikan angket untuk melihat pemahaman mereka terhadap konsep model pembelajaran speaking dengan communicative approach. Berikut adalah hasil pelatihan pada sesi pre-test dan post-test.

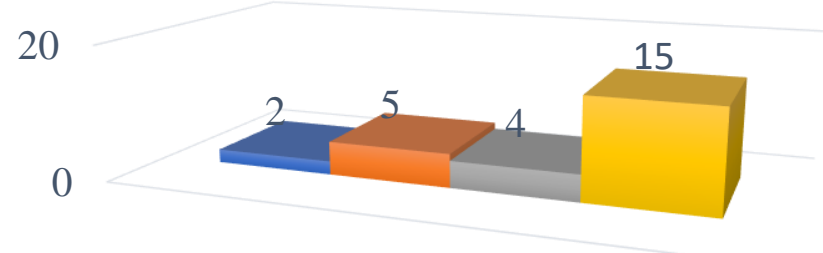

Konsep pembelajaran speaking dengan communicative approach dalam pengajaran bahasa Inggris

Gambar 1. Hasil tes awal (pre-test) sebelum kegiatan dimulai

Gambar 1 di atas menunjukkan bahwa sebagian besar peserta (15) tidak memahami konsep pembelajaran speaking dengan communicative approach dalam pengajaran bahasa Inggris dan dua peserta kurang memahami. Peserta yang sangat memahami 2 peserta dan memahami 5 peserta serta yang kurang memahami sebanyak 4 orang.

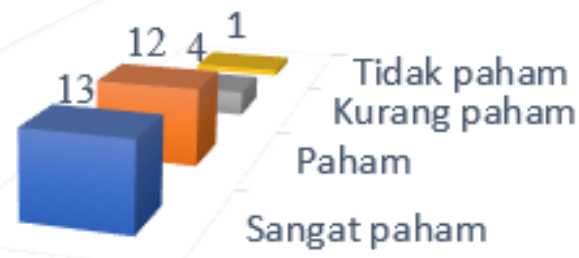

\section{Konsep pembelajaran speaking dengan communicative approach dalam pengajaran bahasa Inggris}

Gambar 2. Hasil tes akhir (post-test) setelah kegiatan

Gambar 2 di atas menunjukkan bahwa sebagian besar peserta sangat memahami sebanyak 13 peserta dan memahami konsep pembelajaran speaking dengan communicative approach setelah mengikuti pelatihan sebanyak 12 peserta. Masih terdapat 4 peserta pelatihan yang masih kurang memahami konsep ini dan diikuti oleh 1 peserta yang masih tidak memahami konsep ini. Namun, sebagian besar dari peserta telah 'sangat memahami' dan 'memahami' konsep ini dengan baik. . Hal ini juga sejalan dengan kegiatan yang dilakukan oleh Candra et al., (2018) yang menyatakan terjadi peningkatan kepercayaan diri setelah pelatihan [40]. Namun, secara keseluruhan semua aspek mengalami peningkatan dengan rerata nilai keseluruhan 37.7 pada pre-test dan 59.8 pada post-test. Hal ini sejalan dengan hasil pelatihan yang dilakukan [41-44].

Tidak hanya itu, pada tahap workshop, para partisipan dimohon buat membuat ataupun 
meningkatkan modul ajar speaking berbasis pembelajaran speaking dengan communicative approach yang cocok dengan modul yang sudah di informasikan oleh para narasumber. Aspek-aspek pembelajaran speaking dengan communicative approach yang dinilai dari materi ajar yang dikembangkan oleh para peserta pelatihan adalah task yang terdiri dari beberapa stages dan aspek: 1) pre-task; 2) during task; 3) post task; dan 4) faktor kognitif (resource-directing dan resource despersing).

Para guru peserta pelatihan memiliki pengetahuan yang baik dalam pengembangan materi ajar bahasa Inggris speaking setelah mengikuti pelatihan ini. Ini bisa dilihat melalui hasil lembar kerja masing-masing peserta sebagai berikut.

Tabel 2. Hasil penilaian tugas pengembangan materi ajar berbasis pembelajaran speaking dengan communicative approach

\begin{tabular}{|c|c|c|c|c|c|c|c|}
\hline \multirow[b]{2}{*}{ No. } & \multirow[b]{2}{*}{ Nama Peserta } & \multirow{2}{*}{$\begin{array}{l}\text { Pre- } \\
\text { task }\end{array}$} & \multirow{2}{*}{$\begin{array}{c}\text { During- } \\
\text { task }\end{array}$} & \multirow{2}{*}{$\begin{array}{l}\text { Post } \\
\text {-task }\end{array}$} & \multicolumn{2}{|c|}{ Congnitive factors } & \multirow[b]{2}{*}{ SKOR } \\
\hline & & & & & $\begin{array}{l}\text { Resource- } \\
\text { directing }\end{array}$ & $\begin{array}{l}\text { Resource- } \\
\text { dispersing }\end{array}$ & \\
\hline 1. & Emi Kristanti & 76 & 65 & 76 & 70 & 86 & 74,6 \\
\hline 2. & $\begin{array}{l}\text { Sigit Wisnu Hayumurti, } \\
\text { S.Pd. }\end{array}$ & 76 & 60 & 76 & 50 & 50 & 62,4 \\
\hline 3. & Pisca Suma Perari & 76 & 80 & 76 & 66 & 88 & 77,2 \\
\hline 4. & $\begin{array}{l}\text { Rian Sigit Gesang } \\
\text { Permana, M.Pd }\end{array}$ & 76 & 80 & 76 & 83 & 90 & 81 \\
\hline 5. & Shobriyah Nikmah & 76 & 70 & 76 & 87 & 96 & 81 \\
\hline 6. & Novi Anita,S.Pd.I & 76 & 75 & 76 & 80 & 86 & 78,6 \\
\hline 7. & Debi Risandi & 80 & 80 & 80 & 76 & 70 & 77,2 \\
\hline 8. & Eva Sudhaliyanti & 76 & 80 & 76 & 87 & 90 & 81,8 \\
\hline 9. & Dewi Lestari, S.Pd & 76 & 80 & 76 & 70 & 82 & 76,8 \\
\hline 10. & Nur Alfiyani Azizah & 76 & 80 & 76 & 87 & 94 & 82,6 \\
\hline 11. & Ribut Setyowati,S.Pd & 76 & 70 & 76 & 80 & 86 & 77,6 \\
\hline 12. & Arofatun Mukaromah & 76 & 75 & 76 & 50 & 50 & 65,4 \\
\hline 13. & Isnindari, S.Pd. & 76 & 80 & 76 & 83 & 90 & 81 \\
\hline 14. & Tiara Pragaswara & 76 & 75 & 76 & 80 & 88 & 79 \\
\hline 15. & Ica Anggela & 76 & 80 & 76 & 60 & 60 & 70,4 \\
\hline 16. & Dina Mustika Rini & 76 & 80 & 76 & 93 & 92 & 83,4 \\
\hline 17. & Hendra Sukmana, S.S. & 76 & 70 & 76 & 83 & 90 & 79 \\
\hline 18. & Heri Susanto, S.Pd. & 50 & 60 & 50 & 50 & 50 & 52 \\
\hline 19. & Ratna Agestiani & 76 & 80 & 76 & 50 & 60 & 68,4 \\
\hline 20. & Mita Lestari, S.Pd & 76 & 70 & 76 & 72 & 84 & 75,6 \\
\hline 21. & Levy Melia Sefitri & 76 & 75 & 76 & 90 & 82 & 79,8 \\
\hline 22. & Ria Bertha Adelia & 76 & 75 & 76 & 87 & 88 & 80,4 \\
\hline 23. & Nurul Jannah & 76 & 70 & 76 & 90 & 92 & 80,8 \\
\hline 24. & Roro Ningsih & 76 & 70 & 76 & 72 & 86 & 76 \\
\hline 25. & Novita Dianawati, M.Pd & 76 & 60 & 76 & 87 & 94 & 82,6 \\
\hline
\end{tabular}




\begin{tabular}{|c|c|c|c|c|c|c|}
\hline Yosephin Asri Wulandari & 76 & 60 & 76 & 93 & 92 & 83,4 \\
\hline Apria Nitasari & 76 & 75 & 76 & 87 & 96 & 81 \\
\hline Dicky Fajar Yuliansyah & 76 & 60 & 76 & 60 & 60 & 70,4 \\
\hline Rohati & 76 & 65 & 76 & 93 & 92 & 83,4 \\
\hline Emi Kristanti & 76 & 80 & 76 & 87 & 90 & 81,8 \\
\hline
\end{tabular}

Tabel 2 di atas menunjukkan bahwa sebagian besar peserta mampu memahami konsep pembelajaran speaking dengan communicative approach dan mengembangkan materi ajar berdasarkan konsep pembelajaran speaking dengan communicative approach ini. Hanya sebagian kecil yang kurang dan belum memahami pengembangan materi ajar berdasarkan konsep ini. Ini dapat dilihat dari skor rerata pengembangan materi ajar yang mereka lakukan, sebagian besar mendapatkan skor rerata di atas 75 dan hanya sebagian kecil yang mendapatkan skor di bawah 70 .

Berdasarkan wawancara informal yang dilakukan oleh tim, para peserta juga tampak antusias untuk mengimplementasikan konsep pembelajaran speaking dengan communicative approach dalam kelas bahasa Inggris mereka. Berikut adalah kutipan wawancara informal para peserta.

"Aku tertarik mengimplementasikan tata cara ini di kelas aku serta hendak aku integrasikan dengan kelas daring aku" (Peserta 5)

"Pembelajaran speaking dengan communicative approach akan membuat siswa merasa santai dan nyaman untuk membantu mereka menggunakan bahasa sasaran dengan tepat" (Peserta 10)

"Saya yakin ini akan meningkatkan minat belajar dan keaktifan siswa dalam hal komunikasi dan interaksi Bahasa inggris, meskipun kelas dilaksanakan secara daring. Sangat mungkin!" (Peserta 8)

"Materinya sesuai dengan konteks dunia nyata yang terjadi sekarang. Menarik!" (Peserta 16)

"Pembelajaran speaking dengan communicative approach bisa sekaligus untuk melakukan manajemen kelas dengan menjadikan Bahasa Inggris mudah di pahami meskipun persiapannya perlu waktu lebih namun tidak masalah" (Peserta 23)

Hasil wawancara tersebut menunjukkan bahwa para peserta akan mengimplementasikan konsep pembelajaran speaking dengan communicative approach dalam kelas bahasa Inggris mereka. communicative approach ini juga diharapkan membantu mempersiapkan siswa di Kabupaten Lampung Selatan mampu bertahan untuk meningkatkan kemampuan menggunakan Bahasa inggris mereka.

\section{Pembahasan}

Tujuan dari kegiatan ini adalah untuk: (1) meningkatkan wawasan dan pengetahuan tentang pengembangan/pembuatan model pembelajaran speaking (berbicara) berdasarkan rekayasa faktor kognitif (task complexity) bagi guru-guru bahasa Inggris di Kabupaten Lampung Selatan; dan (2) memberikan keterampilan pengembangan dan penggunaan model pembelajaran speaking (berbicara) berbasis rekayasa faktor kognitif bagi guru guru di kabupaten Lampung Selatan.

Melihat hasil angket untuk melihat kemampuan awal dan akhir para peserta, terdapat 
perbedaan yang cukup nyata sebelum dan setelah pelatihan dilakukan. Dengan kata lain, pelatihan ini telah mampu meningkatkan wawasan dan pengetahuan tentang pembelajaran speaking dengan communicative approach. Selain itu, berdasarkan penilaian materi ajar yang dikembangkan oleh para peserta pelatihan, dapat dilihat juga bahwa mereka telah mampu memahami dan mengimplemtasikan konsep pembelajaran speaking dengan communicative approach rekayasa kognitif dalam bentuk materi ajar. Dengan kata lain, para peserta telah memiliki keterampilan untuk mengembangkan materi ajar berbasis pembelajaran speaking dengan communicative approach rekayasa faktor kognitif.

Hasil wawancara juga menunjukkan antusiasme dan keyakinan para peserta bahwa pembelajaran speaking dengan communicative approach akan membawa dampak positif bagi siswa di kelas bahasa Inggris mereka. Hal ini berarti bahwa mereka percaya model ini akan membantu meningkatkan kemampuan komunikasi dan interaksi siswa mereka [45] karena sebagian besar para peserta telah memahami konsep pembelajaran speaking dengan communicative approach berdasarkan rekayasa faktor kognitif ini [46].

\section{KESIMPULAN}

Kegiatan pengabdian kepada masyarakat ini telah mencapai tujuan yaitu: (1) meningkatkan wawasan dan pengetahuan tentang pengembangan/pembuatan model pembelajaran speaking (berbicara) berdasarkan rekayasa faktor kognitif (task complexity) bagi guru-guru bahasa Inggris di Kabupaten Lampung Selatan; dan (2) memberikan ketrampilan pengembangan dan penggunaan model pembelajaran speaking (berbicara) berbasis rekayasa faktor kognitif bagi guru guru di kabupaten Lampung Selatan. Hal ini dapat dilihat dari hasil pre-test dan post-test. Hasil penilaian lembar kerja dan wawancara tak terstruktur dengan para peserta juga menunjukkan bahwa sebagian besar peserta mampu memahami konsep pembelajaran speaking dengan communicative approach dan mengembangkan materi ajar berdasarkan konsep pembelajaran speaking dengan communicative approach rekayasa faktor kognitif. Dengan demikian, dapat dikatakan bahwa peserta merasakan manfaat setelah berpartisipasi dalam kegiatan pelatihan ini.

\section{UCAPAN TERIMA KASIH}

Pada kesempatan yang berharga ini, tim pengabdian mengucapkan terima kasih kepada LPPM Universitas Lampung yang telah mendanai kegiatan pengabdian kepada masyarakat ini melalui Hibah Pengabdian Kepada Masyarakat Skema Unggulan

\section{Daftar Pustaka}

[1] Setiyadi, B. (2012). Mengurai Benang Kusut Pembelajaran Bahasa Inggris. Retreived from https://www.kompasiana.com/kristianadiputra/551930a681331117759de0e2/mengurai-benang-kusutpembelajaran-bahasa-inggris?page=all\&page_images=1, on 15 August 2021 .

[2] Saragih, A. (2009). Penguasaan bahasa inggris lemah. Retreived from Harian Sumut Pos http://www.hariansumatraposts.com/2009/12/23408, on 15 August 2021.

[3] Mahpul, M., \& Oliver, R. (2018). Task Complexity In Dialogic Oral Production By Indonesian Efl Learners. Asian EFL, 20(2), 28-59.

[4] Na, Z. (2007). A study of high school students' English learning anxiety. The Asian EFL Journal, 9(3), 2234.

[5] Rahim, P. R. M. A., Ahmad, N., \& Rosly, N. (2004). Task-based approach as a teaching strategy in promoting the speaking skill. In J. Mukundan, D. Z. Abidin, \& A. A. Hussin (Eds.), ELT Matters 1: Issues in English language learning and teaching (pp. 173-180). University Putra Malaysia Press. 
[6] Tsai, C. I. (2003). Anxiety and beliefs about language learning: a study of Taiwanese college students learning English. University-Kingsville.

[7] Brumfit, C., \& Johnson, K. (1979). The communicative approach to language teaching. Oxford University Press.

[8] Ellis, R. (2003). Task-based language teaching and learning. Oxford University Press.

[9] Ellis, R. (2005). Instructed language learning and task-based teaching. In E Hinkel (Ed.), Handbook of research in second language teaching and learning (pp. 713-728). Routledge.

[10] Long, M. H. (1991). Focus on Form: A design feature in language teaching methodology. In K. Bot, R. B. Ginsberg, \& C. C (Eds.), Foreign language research in cross-cultural perspective (pp. 39-52). John Benjamins Publishing Company.

[11] Long, M. H., \& Crookes, G. (1992). Three approaches to task-based syllabus design. TESOL Quarterly, 26(1), 27-56.

[12] Nunan, D. (2004). Task-based language teaching. Cambridge University Press.

[13] Ong, J., \& Zhang, L. J. (2010). Effects of task complexity on the fluency and lexical complexity in EFL students' argumentative writing. Journal of Second Language Writing, 19(4), 218-233. https://doi.org/10.1016/j.jslw.2010.10.003

[14] Prabhu, N. (1987). Second language pedagogy. Oxford University Press.

[15] Van den Branden, K. (2006). Task-based language education. From theory to practice. Cambridge University Press.

[16] Van den Branden, K., Bygate, M., \& M, N. J. (2009). Tasked-based language teaching: introducing the reader. John Benjamins Publishing Company.

[17] Skehan, P. (2003). Task-based instruction. Language Teaching, 36, 1-14.

[18] Gass, S., Mackey, A., \& Ross-Feldman, L. (2011). Task-based interactions in classroom and laboratory settings. Language Learning, Supplement (1), $189-220$.

[19] Gilabert, R. (2005). Task complexity and L2 narrative oral production. Unpublished Ph. D. dissertation. University of Barcelona, Spain.

[20] Robinson, P. (2001). Task complexity, cognitive resources, and syllabus design: a triadic framework for examining task influences on SLA. In Robinson, P. (Ed.), Cognition and Second Language Instruction, 287-318.

[21] Robinson, P. (2003). The cognitive hypothesis, task design, and adult task-based language learning. Second Language Studies, 21(2), 45-105.

[22] Robinson, P. (2005). Cognitive complexity and task sequencing: studies in a componential framework for second language task design. Review of Applied Linguistics in Language Teaching, 43, 1-32.

[23] Robinson, P. (2011). Task-based language learning: a review of issues. Language Learning, Supplement, $1-36$.

[24] Skehan, P. (1996). A Framework for the implementation of task-based instruction. Applied Linguistics, 17, 38-62.

[25] Yuan, F., \& Ellis, R. (2003). effect of pre-task planning and on-line planning on fluency, complexity, and accuracy in L2 monologic oral production. Applied Linguistics, 24, 1-27.

[26] Yuan, F., \& Ellis, R. (2005). The effect of careful within-task planning on oral production and written task performance. In R. Ellis (Ed.), Language learning \& language teaching: planning and task performance in second language (pp. 167-192). John Benjamins Publishing Company.

[27] Mahpul, \& Nurweni, A. (2016). Pengembangan model pembelajaran berbasis task untuk meningkatkan kemampuan berbicara mahasiswa. Penelitian Hibah Dikti.

[28] Samuda, V., \& Bygate, M. (2008). Tasks in second language learning. Palgrave.

[29] Robinson, P. (2007). Criteria for classifying and sequencing pedagogic tasks. In M. P. Garcia Mayo (Ed.), Investigating tasks in formal language teaching: $S L A$ (pp. 7-27). Multilingual Matters.

[30] Hinkel, E. (2011). Handbook of research in second language teaching and learning. In Handbook of Research in Second Language Teaching and Learning (Vol. 2). https://doi.org/10.4324/9780203836507. 
[31] Pateda, M. (1990). Sosiolinguistik. Gadjah Mada University Press.

[32] Pannen, P., Mustafa, D., \& Sekarwinahyu, M. (2001). Konstruktivisme dalam pembelajaran. Jakarta: Depdiknas.

[33] Robinson, P. (2001). Task complexity, task difficulty, and task production: Exploring interactions in a componential framework. Applied Linguistics, 22(1), 27-57.

[34] Ahmadian, J. M., \& Tavakoli, M. (2010). The effects of simultaneous use of careful online planning time and task repetition on accuracy, complexity, and fluency in EFL learners' oral production. Language Teaching Research, 15(1), 35-59.

[35] Foster, P., \& Tavakoli, P. (2009). Native speakers and task performance: Comparing effects on complexity, fluency, and lexical diversity. Language Learning, 59(4), 866-896.

[36] Philp, J., Oliver, R., \& Mackey, A. (2006). The impact of planning time on children task-based interactions. System, 34, 547-565.

[37] Kim, Y. (2009). The effect of task complexity on learner-learner interaction. System, 37(2), 254-268.

[38] Michel, C. M., Kuiken, F., \& Vedder, I. (2007). The influence of complexity in monologic versus dialogic tasks in Dutch L2. IRAL, 45(3), 241-259.

[39] Tavakoli, P. (2009). Investigating task difficulty: Learners' and teachers' perceptions. International Journal of Applied Linguistics, 19(1), 1-25.

[40] Putri, I. G. A. V. W., Santika, I. D. A. D. M., \& Candra, K. D. P. (2018). Pelatihan bahasa Inggris komunikatif untuk kelompok kerja "Serangan Transport" di desa adat Serangan. Jurnal Pengabdian Dan Pemberdayaan Masyarakat, 2(1), 111-119.

[41] Santika, I. D. A. D. M., \& Putri, I. G. A. V. W. (2018). Pelatihan bahasa Inggris komunikatif di desa Canggu, Kuta Utara. SINAPTEK, 2 November, 21-26.

[42] Sudipa, I. N., Brata, F. I. M., Rajeg, I. M., Laksminy, L. P., \& Rahayuni, N. K. S. (2010). Pelatihan bahasa inggris komunikatif bagi kelompok sadar wisata di desa Carang Sari Badung Utara. Udayana Mengabdi, 9(2), 75-78.

[43] Zuhro, C., \& Hermawati, D. A. (2017). Pelatihan bahasa Inggris komunikatif sebagai upaya peningkatan kualitas SDM dalam menghadapi tantangan MEA bagi santriwati Pondok Pesantren Al-Husna Jember. JDinamika, 2(1), 6-10.

[44] Candra, K. D. P., Ariyaningsih, N. N. D., \& Maharani, P. D. (2018). Pelatihan bahasa Inggris komunikatif untuk kelompok life guard di daerah Kuta. Widyabhakti Jurnal IImiah Populer, I (1), 1-6.

[45] Jeon, I.-J., \& Hahn, J. (2006). Exploring EFL teachers' perceptions of task-based language teaching: A case study of Korean secondary school classroom Practice. Asian EFL Journal, 8(1), 1-247.

[46] Abdel-Hadi, A. (2012). Culture, Quality of Life, Globalization and Beyond. Procedia - Social and Behavioral Sciences, 50 (July), 11-19. https://doi.org/10.1016/j.sbspro.2012.08.011 